\title{
EL ESPACIO ESCOLAR COMO OBJETO HISTÓRICO: UNA TRAYECTORIA INTELECTUAL
}

\section{The school space as an historical object: an intellectual career}

\author{
Antonio Viñao ${ }^{\alpha}$ \\ Fecha de recepción: 11/06/2020 • Fecha de aceptación: 12/10/2020
}

Resumen. Este texto constituye un autoanálisis de la trayectoria intelectual que subyace en las investigaciones y publicaciones del autor sobre el espacio y la arquitectura escolares llevadas a cabo desde 1980 hasta la fecha. Dicho autoanálisis se divide en cinco etapas o fases en ocasiones superpuestas. La primera (1970-1982) lleva por título «Entre la praxis reflexiva y la reflexión teórico-práctica»; la segunda (1990-1995), «De la escuela graduada al espacio y la arquitectura escolar»; la tercera (1990-2000), «Espacio y tiempo escolares»; la cuarta (2000-2009), «Entre el análisis microfuncional, la larga duración y las revisiones historiográficas»; la quinta y última (2016-2020), «Revisiones, ampliación de trabajos anteriores y síntesis final».

Palabras clave: arquitectura escolar; edificios y construcciones escolares; espacios escolares.

Abstract. This text constitutes a self-analysis of the intellectual trajectory that underlies the author's research and publications on school space and architecture carried out from 1980 to date. This self-analysis is divided into five stages or phases, sometimes overlapping. The first (1970-1982) is entitled "Between reflective praxis and theoretical-practical reflection"; the second (1990-1995), "From the graduate school to school space and architecture"; the third (1990-2000), "School spaces and times"; the fourth (2000-2009), "Between micro-functional analysis, long duration, and historiographic reviews"; the fifth and last (2016-2020), "Reviews, expansion of previous works and final synthesis".

Keywords: school architecture; school buildings and constructions; school spaces.

\footnotetext{
${ }^{\alpha}$ Facultad de Educación. Universidad de Murcia (España). Campus universitario de Espinardo. 30100 Murcia. España avinao@um.es
} 
Los coordinadores de este monográfico sobre «Arquitectura y espacio escolares» me ofrecieron en su día colaborar con un artículo científico. Mi trayectoria investigadora y publicista sobre el tema desde 1980 -icuarenta años!- les indujo a ello. Agradezco, por lo que significa, el ofrecimiento, pero me es difícil añadir algo novedoso a dicha trayectoria. De hecho, como se verá, mis últimas publicaciones sobre el tema son más bien síntesis o ampliaciones de trabajos anteriores, escritas, además, no por propia iniciativa, sino a petición ajena. A la vista de ello, lo que les propuse fue un análisis retrospectivo de mis investigaciones y publicaciones sobre el espacio y la arquitectura escolares que, yendo más allá de la simple descripción de las mismas, y situándolas en sus contextos de producción y difusión, pudiera ser útil a quienes trabajan, se interesan o se adentran en este campo y constituyera, a la vez, una reflexión personal sobre algunas de las tensiones, cuestiones o problemas detectados en dicho campo, su situación actual y posibles enfoques y temas de investigación futura. ${ }^{1}$

\section{LOS INICIOS: ENTRE LA PRAXIS REFLEXIVA Y LA REFLEXIÓN TEÓRICO-PRÁCTICA (1970-1982)}

Mis primeras experiencias y contactos con el mundo del espacio, los edificios y la arquitectura escolares fueron de índole práctica y anclados en una realidad concreta: la de un funcionario técnico al servicio del Ministerio de Educación y Ciencia desde julio de 1968 a septiembre de 1982. Un responsable técnico-gerencial, entre otras tareas y a partir de 1970 -en plena reforma educativa y aplicación de la recién aprobada Ley General de Educación-, de la gestión administrativa y financiera de las construcciones escolares en la Delegación Provincial de dicho ministerio en Murcia. Mi tarea no era directamente pedagógica ni arquitectónica, pero debía desarrollarse en equipo, trabajando junto a y en relación

\footnotetext{
${ }^{1}$ Los lectores disponen ya de un texto con un objetivo en buena parte similar. Me refiero al de Agustín Escolano, «Espacios y tiempos en educación», en Educación, Historia y Sociedad. El legado historiográfico de Antonio Viñao, ed. Pedro Luis Moreno Martínez (Valencia: Tirant Humanidades, 2018), 197-213. La diferencia entre dicho trabajo -excelentemente enfocado y llevado a cabo- y el actual es obvia: allí es alguien ajeno a la obra quien la analiza, y aquí es el propio autor. Allí se habla en tercera persona y aquí en primera. Las repeticiones o similitudes son, sin embargo, en más de un aspecto inevitables. Y no solo por la identidad del tema, sino por la semejanza de puntos de vista y enfoques. Intentaré, no obstante, ampliar detalles y aportar aspectos o cuestiones novedosas.
} 
con arquitectos, ${ }^{2}$ arquitectos técnicos, delineantes, empresas constructoras, inspectores de educación, directores escolares, profesorado, alcaldes, concejales, arquitectos municipales y asociaciones de padres y madres o vecinos. Y, por supuesto, a partir de los datos e información suministrados por el Servicio de Planificación y Estadística Educativa, uno más de las diversas dependencias de cuyo funcionamiento y gestión, como secretario provincial, era responsable.

Lo que sucede es que -visto de forma retrospectiva y distanciadadebí ser un funcionario técnico algo atípico: no solo gestionaba, sino que, sobre todo y con mayor placer, reflexionaba sobre mi campo de actuación al mismo tiempo que leía, escribía, estudiaba algunas materias de la licenciatura de sociología, preparaba la tesis doctoral sobre política y educación en los orígenes de la España contemporánea -con especial referencia a la educación secundaria-, impartía clases en la Escuela de Trabajo Social y colaboraba, desde 1975, como profesor e investigador en el Instituto de Ciencias de la Educación de la Universidad de Murcia. ${ }^{3}$

Dejo ahora a un lado los aspectos más estrictamente gerenciales de los que era responsable en el ámbito de las construcciones escolares: planificación y estadística escolar, determinación de necesidades de construcción, ampliación o reparación de edificios escolares, aceptación de solares cedidos por los municipios para su construcción, encargos de proyectos de obra, contratación y recepción de las obras, pagos a las empresas constructoras y dotación de mobiliario y material a los edificios de nueva construcción, así como de profesorado si se trataba de aulas de nueva creación y no de sustitución. Solo me interesa resaltar

\footnotetext{
${ }^{2}$ Hubo en esos años otra vía de contacto y relación con el mundo de la arquitectura, los arquitectos y el urbanismo, si bien desde una perspectiva diferente: la que tuve como secretario de la Comisión Provincial del Patrimonio Histórico-Artístico, dependiente de la Dirección General de Bellas Artes del Ministerio de Educación y Ciencia, en relación con la aprobación o no de proyectos de obras de todo tipo en edificios o zonas protegidas -a mi juicio muy deficientemente- desde un punto de vista histórico-artístico.

${ }_{3}^{3}$ Para más detalle sobre estos años y tareas, véase Dolores Carrillo Gallego y José Damián López Martínez, "Antonio Viñao y la Universidad de Murcia», y María José Martínez Ruiz-Funes y Ana Sebastián Vicente, «Historia de la educación en y desde Murcia», en Educación, Historia y Sociedad, Educación, Historia y Sociedad. El legado historiográfico de Antonio Viñao, ed. Pedro Luis Moreno Martínez (Valencia: Tirant Humanidades, 2018), 21-27 y 47-54, respectivamente. Y, en relación con las investigaciones llevadas a cabo en el Instituto de Ciencias de la Educación, Antonio Viñao, «Espacio, sociedad, educación (entre la memoria y el olvido)», en Sociologías y economía. Homenaje al profesor Juan Monreal (Murcia: Editum, 2014), 33-47 [36-38].
} 
tres aspectos o tensiones a partir de los cuales fui progresivamente yendo más allá de la mera función gerencial.

Uno fue el de la tensión existente entre las necesidades de escolarización y los medios o recursos financieros disponibles. Una tensión que condicionaba las decisiones a tomar en relación con el tipo de centro escolar a construir, sobre todo en unos años, los setenta, en los que dichas necesidades y la demanda social iban siempre por delante de los recursos. Había que elegir: ¿solo aulas o menos aulas, pero con espacios para laboratorios, comedor escolar, gimnasio, biblioteca, zonas de recreo y deportivas, etc.?, ¿proyectos definitivos o progresiva y anual o bianualmente ampliables gracias a un diseño modular y en función de las necesidades de cada momento?, ¿cuál era el mínimo esencial desde el punto de vista escolarizador, al menor coste y con gastos de mantenimiento asimismo mínimos?, etc. La necesidad de adoptar una u otra decisión llevó, por la misma naturaleza de las cosas, a trabajar, codo con codo, con los dos arquitectos de la Unidad Técnica de Construcciones Escolares de la Delegación Provincial -ocupábamos dependencias contiguas- en el diseño de un tipo de edificio escolar digno, pero de bajo coste, mantenimiento fácil y ampliable mediante módulos y proyectos sucesivos en función de las cambiantes necesidades de escolarización. Al mismo tiempo, también en función de los recursos, iban aprobándose desde el ministerio, o mediante convenios entre el ministerio y el ayuntamiento de la capital, planes de construcciones cuyos proyectos de obra fueron realizados por diversos arquitectos de la provincia -el arquitecto-jefe de la referida Unidad Técnica, Manuel García Cerdán, fue durante algún tiempo presidente del Colegio de Arquitectos de Murcia-, lo que me permitió conocer -y tratar, junto, como es obvio, con los arquitectos de la Unidad Técnica que después iban a dirigir las obras-, cuestiones relativas, por ejemplo, al diseño y características del edificio, su adecuación al entorno, la necesidad o no de sondeos previos del solar cedido, las peticiones y preferencias de los directores, del profesorado, de la inspección y de las autoridades locales y familias, así como la diversidad de concepciones y diseños del espacio escolar que tenían en mente dichos arquitectos. Todo ello, en síntesis, hizo que me adentrara en un mundo, el de los arquitectos y la arquitectura escolar, hasta entonces desconocido, e incluso a asistir a alguna de las reuniones o encuentros celebrados en Murcia por dichos profesionales.

El segundo aspecto que advertí casi de inmediato -gracias al doble contacto con los arquitectos que proyectaban y/o dirigían la obra y los 
inspectores, directores y el profesorado como futuros o actuales usuarios de la misma- fue la tensión producida por la situación y puntos de vista diferentes que existían entre unos y otros. Unas veces porque espacios proyectados para comedores o bibliotecas, por poner un ejemplo, serían utilizados después como aulas -tal era el desfase en ocasiones entre lo construido y las necesidades de escolarización-. Otras, por pequeños detalles relacionados con la funcionalidad y mantenimiento del edificio que podían ir, por ejemplo, desde la ubicación de la dirección escolar hasta las críticas a la existencia de espacios de difícil control visual -en el edificio escolar o en las zonas no edificadas-, la demanda de mirillas acristaladas en la puerta de las aulas que permitieran ver desde el exterior lo que sucedía en ellas, o de zócalos que facilitaran la limpieza de las paredes de los pasillos y aulas. Y otras, en fin, porque el programa-modelo de necesidades establecido por el ministerio en 1971 para los nuevos centros a construir -rápidamente devaluado por su elevado coste en años sucesivos- preveía no solo el diseño de espacios flexibles para grupos medianos, pequeños y grandes de alumnos, sino también la existencia en el edificio de un espacio central, llamado centro de recursos, en torno al cual girara toda la actividad docente y académica. Es decir, un modelo de organización pedagógica que no llegó a implantarse o materializarse nunca de hecho. Allí aprendí, en la práctica -la teorización vendría después- que las propuestas pedagógicas y arquitectónicas -incluso las mejor intencionadas- podían ir por un lado y la realidad por otro. Que quienes determinaban el uso de los espacios escolares eran, en definitiva, sus usuarios. Y ello en función no tanto de presiones externas -necesidades de escolarización-, cuanto de sus propias necesidades de funcionamiento y de su cultura profesional, organizativa y docente. Una cultura conformada por rutinas y prácticas consolidadas a lo largo del tiempo con el fin de manejar el aula y llevar a cabo su tarea acomodándola, adaptándola a las características del alumnado, y a las exigencias y demandas derivadas de sus colegas de profesión, del entorno, la administración y las familias. Pero esta comprensión teórico-práctica de tales hechos vendría, como dije, más tarde.

El tercer aspecto por el que me interesé durante esos años -origen de la primera publicación sobre el tema, ${ }^{4}$ de otras especializaciones profesionales

4 «El planeamiento urbanístico-docente: un análisis de sus necesidades y problemas», Revista de Educación 264 (1980): 69-80. No está de más indicar que un año antes, en 1979, comencé a trabajar como profesor contratado a tiempo parcial en la sección de Ciencias de la Educación de la Facultad 
y de futuras reflexiones- sería el de las relaciones entre los centros docentes -las construcciones y edificios escolares- y el entorno. $\mathrm{O}$, desde una perspectiva más general, entre los equipamientos públicos, entre ellos los escolares, y el urbanismo u ordenación y usos del territorio.

El contraste entre la legislación o las propuestas geográfico-urbanísticas en cuanto a la ubicación de los centros docentes y la realidad que vivía en el día a día de mi tarea -los solares cedidos por los ayuntamientos con tal fin eran, en general, aquellos desechados para la construcción de viviendas por tratarse de terrenos conformados con material de desecho, inundables, de difícil acceso, sin urbanizar o que requerían costosas obras de cimentación- me hizo ver que, en último término, el espacio escolar-como, en general, el destinado a equipamientos públicos-era un espacio residual: aquel no susceptible de ser urbanizado y destinado a viviendas por los ayuntamientos en mayor o menor connivencia con los promotores particulares. ${ }^{5}$ Por otra parte, la ubicación de un centro docente afectaba a toda una serie de aspectos -tipo y procedencia social del alumnado, distancia a recorrer por el mismo y modo de cubrirla, necesidad o no de transporte y comedor escolares- que determinaban su área de influencia en interacción con las de otros centros más o menos cercanos. En suma, el planeamiento urbanístico, los planes municipales de ordenación urbana y del territorio y, como desarrollo de ellos, los planes parciales, eran, o debían ser, el instrumento y lugar idóneo para establecer, en relación con otros usos del suelo, la ubicación de los centros docentes y, por tanto, los espacios escolares.

El hecho es que, sobre todo en la década de los ochenta, amplié la perspectiva y comencé a preocuparme por todo lo relativo al urbanismo,

\footnotetext{
de Filosofía, Psicología y Ciencias de la Educación de la Universidad de Murcia en la que me integré, a tiempo completo, en 1982 tras haber leído la tesis doctoral en 1980. En esa década, la de los ochenta, dirigiría una tesis doctoral sobre la producción social del espacio escolar en un determinado contexto territorial y en un momento de expansión del mismo (Juan Rosa Gálvez, «Urbanismo y educación. El proceso de implantación de la Educación General Básica en el municipio de Alcantarilla (1970-1985)», Universidad de Murcia, 1990). Habría que esperar a 2011 para que codirigiera, con Gabriela Ossenbach Sauter, otra tesis doctoral, con una idea u objetivo similar, pero en un espacio urbano de mayores dimensiones y en un período de tiempo asimismo más amplio, la de Ana María Montenegro, «Un lugar: la escuela pública. Origen y paradoja (Buenos Aires, Argentina, 15801910)». Madrid, Universidad Nacional de Educación a Distancia, 2011.

5 Juan Monreal, «Contribución metodológica a una sociología del espacio. Producción del espacio escolar». Memoria para el acceso a la cátedra de Sociología. S.a., pero hacia 1985. Documento policopiado.
} 
en especial en relación con los equipamientos colectivos y la ordenación del espacio-territorio, hasta el punto de que, en un determinado momento, me planteé, ante las demandas que recibía para trabajar en este campo, si le dedicaba, o no, más tiempo en detrimento de otras tareas. Fruto de esta fase fueron mi participación en un informe colectivo, encargado por el Ministerio de Obras Públicas y Urbanismo y publicado en 1985, sobre la ordenación territorial del Mar Menor, ${ }^{6}$ mi colaboración durante algún tiempo con una empresa privada -«Espacio y Sociedad»-dedicada a la realización de estudios sociológicos para el sector público o privado y, en especial, de planes de ordenación urbana municipales, ${ }^{7}$ y mi integración, junto con un ingeniero y dos arquitectos, en la realización del plan parcial del campus de la Universidad de Murcia en Espinardo. Mi aportación se redujo, en el primer caso, a los aspectos legales -al fin y al cabo procedía del campo del Derecho-, y en los otros dos, además de dichos aspectos, a la determinación de las previsiones demográficas del municipio -en los planes municipales de ordenación urbana- o de la evolución cuantitativa del alumnado universitario -en el plan parcial del campus universitario-, ${ }^{8}$ así como a la redacción de la memoria escrita en la que se plasmaban la estructura, los objetivos y los fundamentos del plan presentado para su aprobación, y se describían las propuestas y medidas que en el mismo se planteaban. Mi dedicación progresiva a la docencia e investigación en el campo de la educación y, dentro del mismo, a la historia y la política educativa, hicieron que abandonara estas tareas sociológico-urbanísticas. Aunque entonces lo ignorara, la experiencia obtenida -y la concepción del espacio que subyacía en ella- afloraría en mis investigaciones posteriores sobre el espacio escolar.

\footnotetext{
${ }_{6}^{6}$ Varios autores, Ordenación territorial del Mar Menor y su entorno. Murcia: Centro de Estudios de Ordenación del Territorio y del Medio Ambiente, Ministerio de Obras Públicas y Urbanismo, 1985. Nada de lo allí propuesto o dicho se cumplió. Hoy, cuando escribo estas líneas, el Mar Menor es un mar muerto a causa de la especulación urbanística, la mala planificación territorial, la agricultura intensiva y, sobrevolando todo ello, la corrupción política, la ignorancia ambiental y la codicia individual. Entre todos lo mataron y nadie quiere saber quién ha sido.

7 Para más detalle, Viñao, «Espacio, sociedad, educación (entre la memoria y el olvido)», 34-35.

8 Unos años antes había colaborado en un libro colectivo: Juan Monreal (dir.), Libro blanco de la Universidad de Murcia: análisis y perspectivas. Murcia: Instituto de Ciencias de la Educación, 1979.
} 


\section{DE LA ESCUELA GRADUADA AL ESPACIO Y LA ARQUITECTURA ESCOLARES (1990-1995)}

No tengo hoy dudas: el interés académico-científico por el espacio y la arquitectura escolares surgió, en mi caso, a partir y dentro -no al margen o después- de las investigaciones y trabajos llevados a cabo en la segunda mitad de la década de los ochenta sobre la génesis y lenta implantación en España de la escuela graduada. ${ }^{9}$ Este nuevo modelo de organización escolar exigía, pese al recurso a fórmulas provisionales como el doble turno o la graduación a distancia, un nuevo tipo de edificio. Implicaba una nueva concepción pedagógica y arquitectónica del espacio escolar. Y aunque sea cierto que tanto en España como en otros países se publicaron en el siglo XIX libros de arquitectura escolar en los que se desconocía o solo se apuntaba, como una opción más, dicho modelo, el hecho es que sería a partir de su generalización en los años finales de dicho siglo y el primer tercio del XX cuando puede hablarse, en España, de la arquitectura escolar como una especialidad más dentro de la arquitectura civil. Y, junto a ello, cuando proliferarían los trabajos sobre dicha especialidad.

Muestra de que el interés por el espacio escolar estaba ya implícito, presto a salir, en la década de los ochenta, sería una comunicación presentada en 1985, en el coloquio de la SEDHE de dicho año celebrado en Santiago de Compostela, sobre los diversos modos de distribución y los usos del espacio del aula y del centro docente en los institutos de segunda enseñanza originados a partir del acceso de las mujeres a dicho nivel educativo en 1910 como alumnas oficiales. ${ }^{10}$ Se trataba, es cierto, solo de un breve trabajo sobre una cuestión puntual, pero ya anticipaba una concepción del espacio escolar como lugar o territorio a conformar por

\footnotetext{
9 Fundamentalmente de «Cartagena 1900. Los orígenes de la escuela graduada pública en España», en La educación en la España contemporánea. Cuestiones históricas. Libro de homenaje a Ángeles Galino, ed. Julio Ruiz Berrio (Madrid: Sociedad Española de Pedagogía, 1985), 144-150, y, sobre todo, Innovación pedagógica y racionalidad científica. La escuela graduada pública en España (18981936) (Madrid: Akal, 1990). Sobre dichos trabajos, y otros posteriores en relación con el tema, remito a la excelente y bien contextualizada aportación de María del Mar del Pozo Andrés, «Historiografía sobre la escuela graduada: perspectivas internacionales», en Educación, Historia y Sociedad, Educación, Historia y Sociedad. El legado historiográfico de Antonio Viñao, ed. Pedro Luis Moreno Martínez (Valencia: Tirant Humanidades, 2018), 167-195.

10 «Espacios masculinos, espacios femeninos. El acceso de la mujer al bachillerato», en Mujer y educación en España, 1868-1975. VI Coloquio de Historia de la Educación (Santiago de Compostela: Universidad de Santiago, 1990), 567-577.
} 
los usuarios, que iba más allá de su diseño y materialización arquitectónica. La culminación de este interés, tras años de reflexión y lecturas, sería la coordinación y los trabajos publicados en el número 12-13 de la revista Historia de la Educación con el título de «El espacio escolar en la historia», fechado en 1993-94 pero aparecido en 1994-95. ${ }^{11}$

Puede afirmarse que, al menos en España y en relación con el tema del espacio y la arquitectura escolares, hay un antes -vacío casi total- y un después -creciente interés- de la aparición de este número monográfico de la revista Historia de la Educación. Un antes y un después extensible a Brasil gracias, sobre todo, a la publicación en formato libro de dos de sus trabajos en 1998, en excelente traducción de Alfredo Veiga-Neto. ${ }^{12}$ Dicho esto, también hay que señalar dos hechos. Uno es que ya por entonces el tema venía siendo objeto de atención por historiadores de otros países. En Francia, por ejemplo, el Museo Nacional de Educación de Rouen, en el marco de una investigación cuatrienal del Instituto Nacional de Investigaciones Pedagógicas, había emprendido en 1980 una encuesta sobre el edificio escolar en dicho país en el siglo XIX que sería el origen de varias publicaciones, dos de ellas incluidas en 1982 en la revista Histoire de l'Éducation. ${ }^{13}$ En el Reino Unido, Malcom Seaborne había publicado en 1971 el primer tomo de su historia de la

\footnotetext{
${ }_{11}$ Dos observaciones complementarias: durante buena parte de los años ochenta y noventa, y en una época en la que el profesorado gozaba de mayor libertad para determinar los contenidos de la materia impartida -hoy sería imposible- la enseñanza de la disciplina de Historia de la Educación la organicé en torno a tres grandes temas: oralidad, escritura e imagen a través de la historia y la historia del espacio y del tiempo escolares. No había, pues, divergencia entre lo que investigaba y lo que enseñaba en el aula.

En segundo lugar, desde mediados de los ochenta y durante los 40 años que cubre este texto, la biblioteca de Historia de la Educación de la Universidad de Murcia fue nutriéndose de libros y documentos de índole general o especifica -con abundante presencia de fuentes primarias españolas o de otros países- sobre el espacio y la arquitectura escolar. Sin esta dotación bibliográfica no hubiera podido llevar a cabo mis investigaciones. En general, aunque no siempre, dichos fondos fueron adquiridos con cargo a sucesivos proyectos de investigación de entre los cuales, por su relación más directa con el tema, menciono los titulados «El espacio y el tiempo escolares en su perspectiva histórica» (1994-1995) financiado por la Dirección General de Investigación Científica y Técnica del Ministerio de Educación, y «Cultura material de las instituciones educativas en la España del siglo XX. Arquitectura y mobiliario escolares y material científico-pedagógico» (2004-2007), financiado por el Ministerio de Ciencia y Tecnología. La práctica totalidad de los libros que menciono en mis publicaciones, $\mathrm{y}$ en este texto, se hallan en dicha biblioteca o en mi biblioteca personal.
}

12 Antonio Viñao y Agustín Escolano, Currículo, espaço e subjetividade. A arquitectura como programa. Rio de Janeiro: DP\&A Editora, 1998.

${ }^{13}$ Serge Chassagne, «El edificio escolar en Francia en el siglo XIX. Informe de investigación», Historia de la Educación 12-13 (1993-94): 569-572. 
arquitectura y organización de la escuela inglesa desde 1370 a 1870, y en 1977, junto con Roy Lowe, el segundo tomo que cubría el siglo transcurrido entre 1870 y 1970, ${ }^{14}$ y en 1989 David Hamilton había publicado Towards a Theory of Schooling donde analizaba el paso desde la enseñanza mutua a la simultánea y la génesis de la identificación entre clase y aula. ${ }^{15}$ Por último, en el VIII congreso de la ISCHE celebrado en Parma en 1986 sobre Compulsory education: schools, pupils, teachers and methods, habían presentado comunicaciones sobre el tema historiadores de diversos países como Peter Cunningham, Isidoro González Gallego, Attila Horvarth o Martii T. Kuikka, y en 1991 aparecía en Brasil Arquitectura escolar Paulista: 1890-1920, de M. E. P. Corrêa y otros, iniciándose así, en este país, una serie de estudios publicados en los años finales del siglo pasado y comienzos del actual, sobre la arquitectura y el espacio escolares, con especial atención hacia la construcción de los primeros grupos escolares graduados.

Asimismo, de modo en parte similar, el espacio y la arquitectura escolar habían ya comenzado a atraer la atención de arquitectos, historiadores en general, pedagogos e historiadores de la educación en España en la segunda mitad de los ochenta o primeros años de los noventa. Unas veces en publicaciones colectivas -véanse las aportaciones de Almonacid Becquer, González Fraile, Parrado Iglesias y Rivera en el libro colectivo Arquitecturas en Valladolid. Tradición y modernidad, 1900-1950 editado en 1989-, y otras en trabajos individuales como en el caso de Nieto Pino o, sobre todo, Lahoz Abad, o en tesis doctorales como la de Visedo Godínez leída en 1986. Desde una amplia perspectiva, y por la influencia que su lectura tendría en las investigaciones en curso de aquellos años, al menos en mi caso, destacaría la obra de Jaume Trilla. ${ }^{16}$ De otro modo no hubiera sido posible dar forma al mencionado número monográfico de la revista Historia de la Educación de 1993-94 pero aparecido, como se ha dicho, en 1994-95. Quienes, desde diversas perspectivas, colaboraron en

\footnotetext{
${ }^{14}$ Con el fin de no extender este texto con remisiones bibliográficas constantes, tanto en este como en otros de los trabajos que seguidamente se mencionan, remito a Antonio Viñao, «El espacio escolar en su perspectiva histórica. Bibliografía», Historia de la Educación 12-13 (1993-94): 573-594. Ahí podrán encontrarse las referencias completas.

15 David Hamilton, Towards a Theory of Schooling. (London: The Falmer Press, 1989).

16 Jaume Trilla, Ensayos sobre la escuela. El espacio social y material de la escuela (Barcelona: Laertes, 1985)
} 
dicho número por parte española -León Esteban junto con Ramón López Martín, Agustín Escolano, Purificación Lahoz Abad, María del Mar del Pozo Andrés, Pere Solà, Ángel Mato Díaz junto con Aida Terrón Bañuelos, Antón Costa y Narciso de Gabriel-, no solo estaban interesados por el tema, sino que contaban con trabajos anteriores directa o indirectamente relacionados con el mismo. El mero hecho de que propusiera coordinar la parte monográfica del número -algo que debió suceder hacia 1991-92-, y que la propuesta fuera aceptada por la revista, indica que a comienzos de los noventa existía ya en España un cuerpo de conocimientos e investigaciones, y un grupo de historiadores de la educación, con capacidad para hacerse cargo de un monográfico sobre el espacio y la arquitectura escolares.

La simple lectura de mi aportación fundamental, de índole general, ${ }^{17}$ muestra el tránsito, en esos años finales de la década de los ochenta y comienzos de los noventa, desde una cuestión concreta -la génesis y difusión de la escuela graduada y su nueva concepción del espacio y la arquitectura escolares- a planteamientos mucho más amplios de índole no solo histórico-educativa y arquitectónica, sino socio-antropológica o relacionadas con el espacio como objeto de análisis. La simple mención de algunos de los autores citados, como fuentes secundarias, evidencia la amplitud del nuevo enfoque: arquitectos Fernández Alba, Fernández-Galiano-, filósofos -Bentham, Bachelard, Foucault-, sociólogos, antropólogos y estudiosos de la dimensión espacial de la vida humana -Bailly, Sommer, Hall, Picard, Rybczynski, Perec, Paul-Levy, Segoud, Corraliza-, geográfos -Mardsen, Capel-, historiadores del arte -Benévolo, Bonet Correa-, de la técnica y la ciencia -Mumford-y de la educación -Hamilton, Hopman, Hogan, Lesage-, pedagogos -Trilla- o simplemente personajes polifacéticos como Mesmin -político y artista-fotógrafo- preocupados por las relaciones entre la arquitectura, el espacio, la escuela y la infancia. El espacio como lugar y territorio y, como concreción del mismo, el espacio escolar, había pasado a ser el objeto a estudiar y analizar.

\footnotetext{
17 Me refiero, como es obvio, al artículo titulado «Del espacio escolar y la escuela como lugar: propuestas y cuestiones». Otro texto, publicado en la sección de Documentación e Información del monográfico, versaba sobre las «Construcciones y edificios escolares durante el Sexenio Democrático (1868-1874)».
} 


\section{ESPACIOS Y TIEMPOS ESCOLARES (1990-2000)}

En los primeros años de la década de los noventa, en especial a partir de 1994, comencé a elaborar la memoria de acceso a la cátedra de Teoría e Historia de la Educación de la Universidad de Murcia. El núcleo o cuerpo central, por lo que respecta a su enfoque metodológico y fundamentación teórica, estaba constituido por tres capítulos dedicados, desde una doble perspectiva general y aplicada al campo histórico-educativo, a los tres aspectos que, a mi entender, constituyen el soporte de toda actividad humana: el lenguaje o modos de comunicación y estrategias discursivas empleadas en cada momento, el espacio o lugar en el que dicha actividad se desenvuelve, y el tiempo o duración -principio y fin- de la misma.

Los tres capítulos fueron publicados en forma de artículos o libro en 1996 y constituyeron el origen de diversos trabajos aparecidos en años posteriores. ${ }^{18}$ Lo que me interesa ahora destacar es cómo, en estos años finales del siglo pasado, la cuestión del espacio escolar estuvo unida en diversas publicaciones -por tanto, considerada y analizada- a la de los tiempos escolares -en mi caso y en el Agustín Escolano-. ${ }^{19}$ Y ello no solo desde una perspectiva teórica, social y antropológica, sino también desde un enfoque anclado en la comprensión de ambos aspectos -los espacios y tiempos escolares- como elementos constituyentes de la cultura escolar y de la organización y funcionamiento de las instituciones educativas en su conformación actual e histórica. Un enfoque teórico-práctico, este último, que, en cuanto a la docencia de la asignatura de Historia de la Educación, se complementaba, al menos en mi caso, con la realización por el alumnado de trabajos sobre la historia, organización y distribución y usos actuales de los espacios y tiempos en centros docentes concretos. ${ }^{20}$

\footnotetext{
18 Dejo a un lado los trabajos relativos, de modo independiente, a los tiempos escolares -véase, sobre ello, Escolano, «Espacios y tiempos en educación», 208-212-. Indico solo aquellos en los que la cuestión del espacio escolar es tratada junto con la de los tiempos escolares: Espacio y tiempo. Educación e historia (Instituto Michoacano de Ciencias de la Educación, Morelia, 1996), «Lugares y tiempos de la escuela», Vela Mayor 11 (1997): 61-69, "L'espace et le temps scolaires comme objet d'histoire», Histoire de l'Éducation 78 (1998): 89-108. Versión en castellano: «El espacio y el tiempo escolares como objeto histórico», Contemporaneidade e Educaçao V, nº 7 (2000): 93-110.

19 Agustín Escolano, Agustín. Tiempos y espacios de la escuela. Ensayos históricos (Madrid: Biblioteca Nueva, 2000).

20 Una buena parte de dichos trabajos, que incluyen planos, entrevistas, dibujos del alumnado y fotografías, además del texto o memoria, se conservan en el archivo del Centro de Estudios sobre la Memoria Educativa (CEME) de la Universidad de Murcia.
} 
La relectura actual del libro editado por el Instituto Michoacano de la Educación de Morelia (México) en 1996 con el título de Espacio y tiempo. Educación e historia, muestra la continuidad de ciertos temas, autores y lecturas presentes en el artículo publicado varios años antes en el mencionado número monográfico de la revista Historia de la Educación -incluso con transcripciones literales de algunos fragmentos del mismo- y, al mismo tiempo, otros nuevas cuestiones, reflexiones y lecturas procedentes, sobre todo, del ámbito de la historia social y cultural, de la sociología y de la antropología. Así, tras un capítulo introductorio sobre el espacio como posibilidad y límite de la actividad humana, sintetizaba lo dicho en el trabajo anterior sobre la dimensión espacial de dicha actividad y la comprensión del espacio como territorio y como lugar, para pasar de inmediato a tratar los espacios del pasado y de la historia -la cartografía, la geografía histórica o geohistoria, la influencia de la geografía como disciplina en la primera fase de la revista Annales-, las diversas percepciones socio-culturales del espacio, y la necesidad de analizarlo desde la doble perspectiva de los rituales, distancias y jerarquías en su distribución o usos, y de los dilemas o tensiones planteadas entre lo interno-externo -lo que está dentro y lo que está fuera-, lo abierto-cerrado -el grado de porosidad-y lo pequeño-grande. Un doble enfoque -ampliado, como se verá, en un texto posterior de 2016-21 aplicable al espacio escolar en todas sus facetas y dimensiones. El libro incluía un epígrafe sobre el espacio del historiador -el lugar desde el que se piensa, se toman decisiones en la investigación y se escribe, y el debate sobre las relaciones entre lo local, lo regional, lo nacional y lo transnacional, o sea, entre el centro o centros y la periferia-. Y finalizaba con un capítulo de síntesis sobre la evolución del espacio escolar a través de la historia -de la itinerancia a la estabilidad, de la dependencia a la autonomía, de la diversidad a la especificidad-, y sus rasgos básicos como lugar -acotamiento, porosidad, segmentación interna-, en el que se esbozaba una metodología de análisis que iba desde el exterior -emplazamiento- al interior -las diversas dependencias, con usos y funciones distintas, hasta llegar al aula de clase- pasando por las relaciones entre las zonas no

21 «El espacio escolar ¿Cómo abordar un objeto polifacético y multiforme?», en Espacios y patrimonio histórico-educativo, coords. Pauli Dávila Balsera y Luis $\mathrm{M}^{\mathrm{a}}$ Naya Garmendia (Donostia: Erein, 2016), 25-59. 
edificadas y las edificadas, que desarrollaría con mayor detalle en el recién mencionado trabajo de 2016.

\section{ENTRE EL ANÁLISIS MICROFUNCIONAL, LA LARGA DURACIÓN Y LAS REVISIONES HISTORIOGRÁFICAS (2000-2009)}

La confluencia en los primeros años del nuevo siglo entre, por un lado, nuevos trabajos sobre la génesis y difusión de la escuela graduada en España y en otros países, ${ }^{22}$ y la lectura de libros como los de Thomas A. Markus y Bill Hillier y Julienne Hanson, ${ }^{23}$ junto con la consulta de tratados y estudios de arquitectura escolar del siglo XIX y la primera mitad del XX sobre todo los de Bouillon (1834), Mann (1842), Barnard (1848, 2ª edición,

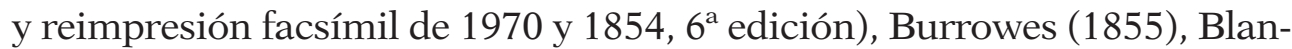
dot (1864), Robson (1874), Narjoux (1877, 1879, 1880, 1881), Nonus (1893), Levant (s.a., pero hacia 1890), Clay (1902), Baudin (1917), Donovan y otros (1921), Chapman y Gilbert (s.a.), Secchi (1927), Debat-Posan (1930), Carbonara (1947), Roth (1957)-, o de libros donde determinados organismos públicos daban cuenta de las edificios escolares construidos o diseñados en diversos países -por ejemplo, Massachusetts EE. UU. (1842), Maine, EE. UU. (1873), Ajuntament de Barcelona (1921, $2^{\mathrm{a}}$ edición)-, ${ }^{24}$ hicieron que dirigiera la atención hacia determinados espacios concretos $\mathrm{y}$, entre otros, el asignado y ocupado por la dirección de los centros docentes.

Este tipo de investigación microfuncional se fundamentaba en dos supuestos: a) la interacción existente entre los distintos espacios de una determinada estructura morfológica a partir de las diversas funciones y usos asignados a los mismos -cómo los espacios quedan «contaminados» por el tipo de actividad que en ellos se lleva a cabo, así como por las personas y objetos que los ocupan-; y b) la existencia, consecuencia en buena parte de lo anterior, de una «lógica social del espacio». Una lógica que hace posible considerarlo como un lenguaje no verbal, como un

\footnotetext{
22 Sobre este tema, y las investigaciones propias y de otros autores, remito de nuevo a del Pozo Andrés, «Historiografía sobre la escuela graduada: perspectivas internacionales».

${ }_{23}$ Thomas A. Markus. Buildings \& Power. Freedom and Control in the Origin of Modern Building Types (London: Routledge, 1993); Bill Hillier y Julienne Hanson. The Social Logic of the Space (Cambridge: Cambridge University Press, 1984).

${ }^{24}$ Los libros enumerados se hallan en la sección dedicada al espacio y la arquitectura y escolares de la biblioteca de Historia de la Educación de la Universidad de Murcia.
} 
texto o discurso susceptible de diversas apropiaciones y lecturas; es decir, de percepciones y significados diferentes.

Solo hacía falta aplicar dichos supuestos teórico-metodológicos al análisis de un espacio escolar específico. Aunque en otros trabajos posteriores me he referido, a modo de ejemplo, a espacios tales como la capilla o la biblioteca, ha sido el asignado a la dirección, su emplazamiento en el edificio escolar, su relación con otras dependencias o espacios -entrada, hall, servicios administrativos, biblioteca, sala de profesores, etc.-, y, sobre todo, su concepción funcional -es decir, de las funciones que se le asignan y la percepción que se tiene de las mismas; del modelo de dirección por el que se opta-, el espacio escolar al que más atención he prestado. ${ }^{25}$

Frente al microanálisis centrado en un espacio-dependencia del centro docente, se halla el análisis macro desde la perspectiva de la larga duración que, cubriendo un extenso período, pone en relación la política de construcciones escolares, los cambios en la concepción y el diseño de los edificios escolares y el proceso de escolarización.

La oportunidad de llevar a cabo un estudio de este tipo vino con la invitación de Agustín Escolano para participar en un libro colectivo que, con el título de Historia ilustrada de la escuela en España. Dos siglos de perspectiva histórica, se publicaría en 2006. Dividido el libro en dos partes, la primera sobre «la escuela en la sociedad liberal (1808-1939)», y la segunda sobre «la escuela en la segunda mitad del siglo XX», se me encargaron sendos capítulos, para cada una de ellas, sobre los espacios de la escuela y la arquitectura escolar que en este caso, como ya iba sucediendo de modo progresivo en trabajos anteriores, irían acompañados de abundantes ilustraciones. ${ }^{26}$

\footnotetext{
25 «Espacios escolares, funciones y tareas: la ubicación de la dirección escolar en la escuela graduada», Revista Española de Pedagogía LXII, no. 228 (2004): 279-303. Número monográfico sobre "Arquitectura y educación: perspectivas y dimensiones» coordinado por Teresa Romañá.

Versión ampliada en inglés: «The School Head's Office as Territory and Place: location and physical layout in the first Spanish graded schools", en Materialities of Schooling. Design - Techology - Objects - Routines, eds. Martin Lawn \& António Nóvoa (Oxford: Symposium Books, 2005), 47-70. Traducción al portugués: «Espaços, usos e funções: a localização e disposição física da direção escolar na escola graduada», en Història da Educação, Arquitetura e Espaço Escolar, orgz. Marcus L. Albino Bencostta (São Paulo: Cortez Editora, 2005), 15-47.

26 «Templos de la patria, templos del saber. Los espacios de la escuela y la arquitectura escolar» $\mathrm{y}$ «El espacio escolar: viejas cuestiones, nuevos escenarios», en Historia ilustrada de la escuela en España.
} 
De nuevo dicha oportunidad volvió a surgir al pedírseme, poco después, en un seminario sobre "La escuela y sus escenarios» del grupo italo-portugués-español SPICAE, que participara con una ponencia sobre el espacio y la arquitectura escolares en la España del siglo XX. ${ }^{27}$ Un texto en el que es cierto que retomaba, transcribía y detallaba lo dicho en los dos anteriores, pero en el que también mostraba la recepción de nuevos trabajos de autores ya conocidos -Escolano, Trilla, Fernández Alba-y de otros hasta entonces no leídos -Burke, Eggermont, Velasco-. Además, incluía un apartado final, de índole reflexiva y metodológica, sobre "la dialéctica entre lo interno y lo externo en los espacios escolares» y la necesidad de distinguir, como ya se venía haciendo en el análisis del currículum, entre los «espacios deseados», los "prescritos», los «reales» y los «vividos». Al fin y al cabo, cuando se nos pide de forma reiterada y sucesiva que escribamos sobre un tema en el que se nos supone "expertos», lo habitual es retomar y utilizar una parte mayor o menor de lo ya dicho y desarrollar, en el nuevo texto, las reflexiones y temas que nos han sugerido nuevas lecturas e investigaciones.

Otro de los indicadores de que hemos pasado a la condición de «expertos», o de que al menos se nos identifica, como investigadores, con un tema determinado, es que se nos pidan revisiones historiográficas o estados de la cuestión sobre el mismo. Esto es lo que sucedió con un trabajo incluido en un libro colectivo, publicado en Brasil en 2009 con el título de História(s) Comparada(s) da Educação, en el que junto con Marcus L. Bencostta, por parte brasileña, llevamos a cabo una revisión comparada de las investigaciones en Brasil y España sobre el espacio y la arquitectura escolares. ${ }^{28} \mathrm{Nada}$ extraño si se tiene en cuenta que quizás sean dos de los países en los que más se han publicado sobre el tema en las últimas décadas.

Dos siglos de perspectiva histórica, dir. Agustín Escolano (Madrid: Fundación Germán Sánchez Ruipérez, 2006), 47-71 y 209-308 respectivamente.

27 «La escuela y sus escenarios en la España del siglo XX: el espacio y la arquitectura escolar», en $L a$ escuela y sus escenarios, eds. Juan Gómez Fernández, Gloria Espigado Tocino y Miguel Beas Miranda (El Puerto de Santa María: Concejalía de Cultura del Ayuntamiento de El Puerto de Santa María, 2007), 9-37.

28 Antonio Viñao y Marcus Levy Bencostta, «Ente a multidisciplinariedade e a história: o espaço e a arquitectura escolares nas recentes historiografias educativas espanhola e brasileira», en História(s) Comparada(s) da Educação, orgz. Marta Maria de Araújo (Brasilia: Liber Livro Editora Ltda., 2009), 23-51. 
Por último, otro texto de síntesis, un artículo -muy citado, no tanto por su contenido cuanto por su accesibilidad en internet- publicado en 2008 en un monográfico de la revista Participación Educativa sobre «Historia de un olvido: patrimonio en los centros escolares», se enmarcaba ya en un enfoque hasta entonces no tenido prácticamente en cuenta por los historiadores de la educación, pero en auge desde principios del nuevo siglo: el de la consideración de los edificios escolares como parte del patrimonio histórico-educativo y, por tanto, como lugares de la memoria escolar. ${ }^{29}$ Una nueva perspectiva que justifica, por ejemplo, que las VII Jornadas científicas de la Sociedad Española para el Estudio del Patrimonio Histórico-Educativo (SEPHE) y V Simposio Iberoamericano de Historia, Educación y Patrimonio Educativo, celebrado en Donostia en 2016, tuvieran por tema «Espacio y Patrimonio Histórico-educativo». ${ }^{30}$

\section{REVISIONES, AMPLIACIÓN DE TRABAJOS ANTERIORES Y SÍNTESIS FINAL (2016-2020)}

Siete años, desde 2009 a 2016, sin publicación alguna sobre los espacios y la arquitectura escolares no significan ausencia de lecturas o reflexiones. Simplemente, indican preferencia o dedicación a otros temas y, quizás también, dificultades de diversa índole para ir más allá de lo ya dicho. No obstante, la consideración académica como conocedor o «experto» en una línea de investigación determinada no se abandona fácilmente. Al igual que la tesis doctoral nos marca y etiqueta para siempre, lo mismo sucede, con los años, con aquellos otros campos en los que investigamos y publicamos con cierta asiduidad. De ahí que las invitaciones y requerimientos sigan en el tiempo, querámoslo o no, forzándonos a revisar y ampliar lo ya dicho, bien en relación con una parcela o

\footnotetext{
29 «Escolarización, edificios y espacios escolares», Participación Educativa 7 (2008): 16-27.

30 Sobre este aspecto y la creación del Museo Virtual de Historia de la Educación (MUVHE) de la Universidad de Murcia, accesible desde 2010, véase Pedro Luis Moreno Martínez, «Memoria escolar y patrimonio histórico-educativo», en Educación, Historia y Sociedad, Educación, Historia y Sociedad. El legado historiográfico de Antonio Viñao, ed. Pedro Luis Moreno Martínez (Valencia: Tirant Humanidades, 2018), 402-408. La primera de las salas del MUVHE, dedicada a los «Espacios y edificios escolares», dispone de sub-salas y visitas relativas a la educación infantil en el siglo XIX, la enseñanza mutua, la enseñanza primaria en mencionado siglo y la escuela graduada en España desde 1899 a 1939.
} 
aspecto concreto, bien mediante recapitulaciones o síntesis clarificadoras.

Del primer tipo -revisión y ampliación de lo escrito en relación con la escuela graduada y las construcciones escolares en España durante el primer tercio del siglo XX-fue la colaboración en el libro-catálogo editado en 2019 con motivo de la exposición organizada por el ayuntamiento madrileño, y comisariada por María del Mar del Pozo, con el título de Madrid, ciudad educadora 1898/1938. Memoria de la escuela pública. ${ }^{31}$ En el mismo, tras relacionar la génesis y difusión de la escuela graduada con la política escolarizadora y el surgimiento de la arquitectura escolar como campo profesional en España, se analizaba el caso madrileño distinguiendo dos fases: la de 1902 a 1922, de enfrentamiento entre el Ministerio de Instrucción Pública y el ayuntamiento de la capital y debilidad de la política escolarizadora, y la de 1922 a 1936, de consenso y acción conjunta de ambos organismos y, en consecuencia, de una mayor acción constructiva de edificios escolares. En este punto, me serví, sobre todo, de los trabajos de María del Mar del Pozo y Francisco Javier Rodríguez Méndez sobre el urbanismo, la escuela graduada y las construcciones escolares en Madrid en esos años. ${ }^{32}$ Todo lo anterior se ponía, por último, en relación -algo novedoso en relación con anteriores trabajoscon la situación deficitaria de las haciendas estatal y municipal, y la opción de las clases acomodadas, desde el último cuarto del siglo XIX, por la escolarización a cargo de las órdenes y congregaciones católicas.

Del segundo tipo -recapitulaciones y síntesis clarificadoras- son dos trabajos. El último en el tiempo, tiene su origen en unas jornadas de Arte y Patrimonio Regional sobre «Espacios para la educación. Arquitectura, ideología e imagen en La Rioja en los siglos XIX y XX»,

\footnotetext{
31 «Escuela graduada y medio urbano: construcciones, edificios y grupos escolares (1898/1936)» y "Graded schools in the urban settings: constructions, buildings and school complexes (1898/1936)», en Madrid, ciudad educadora 1898/1938. Memoria de la escuela pública (Madrid: Ayuntamiento de Madrid. Oficina de Derechos Humanos y Memoria, 2019), 168-265. Dejo a un lado, por tratarse de un tema en estos momentos marginal -pese a su relevancia-, la participación, junto a Rodríguez Méndez y García Salmerón, en el debate sobre «Las construcciones escolares en España en los años veinte y treinta del siglo pasado (la dictadura primorriverista y la Segunda República)», Historia y Memoria de la Educación 11 (2020): 649-673.

32 Entre otros, María del Mar del Pozo Andrés, Urbanismo y educación. Política educativa y expansión escolar en Madrid (1900-1931) (Alcalá de Henares: Universidad de Alcalá, 1999), y Francisco Javier Rodríguez Méndez, «Arquitectura escolar en España (1857-1936). Madrid como paradigma». Tesis doctoral. Departamento de Composición Arquitectónica, Universidad Politécnica de Madrid, 2004.
} 
organizadas por el Instituto de Estudios Riojanos y celebradas en Logroño en noviembre de 2018, y se halla pendiente de publicación en un monográfico de la revista Artigrama sobre arquitectura escolar, coordinado por Mónica Vázquez Ortega. Responde, en cuanto a su contenido, a lo que se me pidió: una visión panorámica de un siglo sobre la «Política educativa, escolarización y construcciones escolares en España (1969-1970)». El anterior, fechado en 2016, también surgió como consecuencia de un encargo, pero de índole muy diferente: la conferencia inaugural de las ya mencionadas VII Jornadas científicas de la SEPHE y V Simposio Iberoamericano de Historia, Educación y Patrimonio Educativo, celebrado en Donostia en dicho año con el tema de «Espacio y Patrimonio Histórico-educativo». Su título, «El espacio escolar. ¿Cómo abordar un objeto polifacético y multiforme?», indicaba ya su índole general y su finalidad metodológica. Aunque en él se abra la puerta a posibles y futuras investigaciones -nunca se deben dar por cerradas-, este trabajo constituye, en estos momentos y por mi parte, la última palabra sobre la cuestión del espacio o espacios escolares. De ahí que me detenga en algunos de los aspectos tratados en el mismo.

El texto se abría con la distinción entre espacios escolares -educación formal-y educativos -educación no formal e informal-para pasar, de inmediato, a mostrar la naturaleza poliédrica, polifacética y multiforme de los primeros -en sí mismos y en sus representaciones, percepciones y apropiaciones-, así como la diversidad de enfoques, perspectivas y miradas desde la que abordarlos. De entre los distintos enfoques posibles, sin desdeñar o desvalorizar otros, se exponían dos de ellos: el antropológico-proxémico, de índole general, centrado en la dimensión espacial de la actividad humana y en la concepción del espacio como un discurso, y, de modo más específico, aquel que parte de la consideración del espacio escolar como lugar.

La mirada antropológico-proxémica muestra la necesidad de tener en cuenta los dilemas o tensiones básicas que genera cualquier espacio diseñado, construido u ocupado. El resultado sería un esquema a aplicar, a modo de rejilla, en su análisis:

1. Lo interno y lo externo: el espacio que delimita lo qué y quién está dentro de lo qué y quién está fuera: los límites y el contorno. 
2. Lo cerrado/acotado y lo abierto: el grado de porosidad o permeabilidad visual, las continuidades y discontinuidades.

3. Lo visible, lo transparente y lo oculto: fundamental en cuanto al control y la vigilancia.

4. Lo pequeño y lo grande como medida o proporción.

5. Lo curvo, lo angulado y lo rectilíneo como estética con significado y en relación con el control y la vigilancia.

6. Lo propio, lo ajeno y lo común como espacio social o territorio y fuente de identidad.

7. Lo superior o inferior: arriba, abajo, órdenes jerárquicos, distancias.

8. Lo que está delante y lo que está detrás: lo que precede, antecede o prepara, y lo que no es visible o no está directamente accesible.

9. Lo próximo y lo lejano: el sentido de la distancia, lo accesible y lo remoto.

10. Lo que queda a un lado u otro: izquierda, derecha, frontal.

11. Lo diáfano o segmentado: porosidad interior.

12. Lo análogo y lo diferente: la comparación como modo de comprensión y asimilación o extrañamiento y distinción.

13. Lo que constituye u ocupa el eje o centro y la periferia.

En cuanto a la consideración del espacio escolar como lugar, desarrollaba, con mayor detalle y ejemplos, una metodología ya propuesta en «Del espacio escolar y la escuela como lugar», un artículo publicado ¡veintiséis años antes!, en 1993-94: la de las matrioskas rusas. Un método de análisis de la dimensión espacial de los centros docentes consistente en ir yendo desde el exterior al interior, como si estuviéramos eliminando las sucesivas capas de una cebolla hasta llegar a su núcleo central. Es decir, desde el emplazamiento o ubicación en relación con otros espacios a las mínimas unidades o elementos espaciales a considerar-los casilleros del profesorado o las cabinas del alumnado, rincones con usos asignados formal o informalmente, etc.- pasando sucesivamente por la imagen externa que se ofrece al viandante o recién llegado, los elementos de separación o cierre del espacio acotado, las zonas no 
edificadas y sus relaciones con las edificadas, la fachada y entrada principal, la distribución interna de los espacios edificados en función de sus usos y de las actividades que en ellos se realizan, y los espacios destinados a aulas o actividades docentes.

En el apartado relativo a los espacios-aula, tras analizar el modelo de las infant schools inglesas surgido en las primeras décadas del siglo XIX, así como sus adaptaciones en otros países y la pervivencia de algunos de sus elementos, como la gradería, hasta el siglo XX, el texto finalizaba con una serie de reflexiones sobre un tema al que venía dando vueltas, y sigo dándole, desde hacía años: el de las formas intermedias de organización del espacio en el paso de la escuela unitaria, de un solo maestro o maestra, a la escuela graduada o grupo escolar. ${ }^{33}$

La escuela unitaria, con un solo maestro o maestra y alumnado de diversas edades y conocimientos, ha sido objeto de estudios habitualmente relacionados con la escolarización en el mundo rural o con el medio urbano, en este caso hasta el primer tercio del siglo pasado. Asimismo, la génesis y difusión de la escuela graduada con diversos maestros y un maestro-director, y el alumnado clasificado en grados o cursos ubicados en aulas separadas, formando parte por lo general de un mismo edificio escolar construido con tal fin, viene siendo, cada vez más, objeto de estudio en diversos países.

Tales estudios, sin embargo, prestan escasa o nula atención, a los modos de escolarización y distribución y usos del espacio escolar que facilitaron mental, arquitectónica y pedagógicamente el tránsito de un modo de escolarización a otro.

En algunos países, tal es el caso español, ante la lentitud y dificultades -en especial económicas, por el coste de los edificios exigidos por el nuevo modo de escolarización- se recurrió a medidas provisionales conocidas con la expresión de «graduación sin graduadas»; es decir, graduación sin construcción de grupos escolares. Tales medidas fueron, en síntesis:

\footnotetext{
33 En lo que seguidamente se dice, transcribo casi en su totalidad la propuesta presentada de modo conjunto con María del Mar del Pozo -posteriormente no expuesta-, en el congreso de la ISCHE celebrado en Porto en 2019. Todo quedó, por ahora, en un programa de trabajo a desarrollar y ampliar. Para más detalle con ilustraciones y referencias bibliográficas, remito a lo dicho en «El espacio escolar ¿Cómo abordar un objeto polifacético y multiforme?», 50-55.
} 
1. El desdoblamiento de aquellas escuelas con maestros auxiliares mediante su conversión en maestros independientes habilitando nuevos locales o dividiendo en dos aulas dos aulas el aula preexistente.

2. El doble turno de mañana y tarde allí donde había una sola aula.

3. La coeducación allí donde solo hubiera un aula de niños y otra de niñas.

4. La graduación a distancia mediante la unificación legal en un solo grupo de escolar de aulas-escuela físicamente distantes e independientes.

Con todo el interés que puedan tener estas medidas provisionales, tanto desde el punto de vista de los modos de escolarización como de los usos del espacio escolar, es obvio que dichas medidas evidenciaban la necesidad de construir nuevos edificios acordes con las exigencias técnico-higiénico-pedagógicas de ese nuevo modelo de organización escolar que era la escuela graduada.

En dicho tránsito surgieron, evolucionaron y perduraron, durante cierto tiempo, diversos modos de escolarización y distribución y uso del espacio escolar de naturaleza intermedia o de transición entre uno y otro modelo. Modos que, sin responder material, organizativa y pedagógicamente al modelo de escuela graduada o grupo escolar de forma plena, facilitaron mental, arquitectónica y pedagógicamente el tránsito de un tipo de escolarización a otro. Tres de ellos fueron:

1. El pupil-teacher system, o sistema inglés, establecido en el Reino Unido a mediados del siglo XIX como modelo de formación de maestros, en el que el aula podía ser dividida en varios espacios separados mediante cortinas o mamparas donde un maestro auxiliar, en formación, enseñaba a un grupo de alumnos previamente clasificados.

2. El aula con espacios anexos, conocidos como recitations rooms. Un modo de escolarización utilizado en Estados Unidos durante el siglo XIX, en el que un maestro auxiliar, alumnos aventajados, o el mismo maestro titular de la escuela, tomaban la lección o realizaban actividades de repaso con un grupo de alumnos segregado con tal fin del grupo general.

3. El Akron plan, un modelo de organización del espacio religioso-escolar, intermedio entre el sistema lancasteriano o monitorial y el 
pupil-teacher system, utilizado en Estados Unidos entre 1869 y 1920 en las Sunday schools de un buen número de iglesias evangélicas. En dicho modelo de distribución del espacio, una gran aula con forma de anfiteatro, y regida por un solo maestro, era dividida en diversos espacios separados por mamparas movibles donde se distribuía, debidamente clasificado, el alumnado con su maestro-auxiliar al frente.

\section{PALABRAS FINALES}

No existe un objeto o tema, real o imaginado, que al ser considerado, visto, desde lugares diferentes siga siendo el mismo objeto o tema. El lugar en el que nos situamos determina lo que vemos y cómo lo vemos, así como lo que queda fuera de nuestra visión. En el caso del espacio escolar, un objeto polifacético y multiforme, esta perspectiva móvil se amplifica y refuerza. Y no porque, como es sabido, un paisaje o espacio determinado no sea el mismo paisaje o espacio para un o una artista que para quien lo contemple desde la milicia, la topografía, la geografía, la promoción inmobiliaria, como simple paseante y así hasta el infinito. Hablo del mundo de quien investiga en este campo. A lo largo de los cuarenta años dedicados al tema he leído y conversado con arquitectos, geógrafos, urbanistas, ingenieros, pedagogos, antropólogos, sociólogos, profesores, filósofos e historiadores en general o sectoriales -de la educación, como es obvio, pero también del arte-, entre otros profesionales o miembros de diversos campos académicos. Siempre me han hecho ver, con sus distintos enfoques e intereses, aspectos o matices que yo no había entrevisto o que había dejado a un lado. Espero que también haya sucedido lo mismo con lo que he escrito o dicho, como espero que este autoanálisis reflexivo sea útil o interese en mayor o menor medida a quienes lo lean. De un modo u otro, lo que sí es cierto es que todo ha sido escrito o dicho teniendo en mente, de modo consciente o inconsciente, lo afirmado en 2005 por Catherine Burke en la introducción al número monográfico de la revista Paedagogica Histórica sobre "Containing the school child: architectures and pedagogies»

Más que ser visto como un 'contenedor' pasivo y neutral, si es que eso se reconoce, el edificio escolar, sus diversos espacios, los 
muros, las paredes, ventanas, puertas y muebles, junto con los rincones exteriores, jardines y espacios abiertos son aquí considerados como elementos activos que conforman la experiencia de la escuela y la comprensión de la educación. ${ }^{34}$

\section{Nota sobre el autor}

Antonio Viñao Frago es doctor en Derecho y colaborador Honorario del Departamento de Teoría e Historia de la Educación de la Universidad de Murcia. Ha sido miembro del Comité Ejecutivo de la International Standing Conference for the History of Education (1996-2000) y presidente de la Sociedad Española de Historia de la Educación (2001-2005), así como director del Centro de Estudios sobre la Memoria Educativa de la Universidad de Murcia (2009-2013) y de la revista Historia y Memoria de la Educación (2014-2019).

Sus campos de investigación prioritarios son la historia de la alfabetización y de la cultura escrita, la escolarización y la enseñanza secundaria, así como la historia del currículum (espacios y tiempos escolares, disciplinas), del profesorado (profesionalización, autobiografías y memorias), de la memoria escolar y el patrimonio histórico-educativo, y de la relación entre las culturas escolares y las reformas y políticas educativas.

\section{REFERENCIAS}

Burke, Catherine. "Introduction. Containing the School Child: Architectures and Pedagogies», Paedagogica Historica 41, no. 4\&5 (2005): 489-494.

Burke, Catherine e Ian Grosvenor, School. London: Reaktion Books, 2008.

Carrillo Gallego, Dolores y José Damián López Martínez. «Antonio Viñao y la Universidad de Murcia», en Educación, Historia y Sociedad, Educación,

\footnotetext{
${ }^{34}$ Catherine Burke. «Introduction. Containing the School Child: Architectures and Pedagogies», Paedagogica Historica 41, no. 4\&5 (2005): 494-495. Este texto fue escrito antes de la Covid-19. Releído y revisado, antes de su entrega, en plena fase de 'desescalada', me sugiere muchas cuestiones de las que solo menciono dos. La primera es que buena parte de los trabajos que en el futuro se publiquen sobre el espacio escolar versarán sobre el espacio y la enseñanza virtuales, sus rasgos diferenciales con el espacio analógico o físico, posibilidades y limitaciones, etc., así como sobre la experiencia en curso de educación a distancia La segunda, es que tampoco el ciberespacio es un 'contenedor' pasivo y neutral por más que así nos lo presenten o parezca.
} 
Historia y Sociedad. El legado historiográfico de Antonio Viñao, ed. Pedro Luis Moreno Martínez, 21-44. Valencia: Tirant Humanidades, 2018.

Del Pozo Andrés, María del Mar. Urbanismo y educación. Política educativa y expansión escolar en Madrid (1900-1931). Alcalá de Henares: Universidad de Alcalá, 1999.

Del Pozo Andrés, María del Mar. «Historiografía sobre la escuela graduada: perspectivas internacionales», en Educación, Historia y Sociedad, Educación, Historia y Sociedad. El legado historiográfico de Antonio Viñao, ed. Pedro Luis Moreno Martínez, 167-195. Valencia: Tirant Humanidades, 2018.

Escolano, Agustín. Tiempos y espacios de la escuela. Ensayos históricos. Madrid: Biblioteca Nueva, 2000.

Escolano, Agustín. «Espacios y tiempos en educación», en Educación, Historia y Sociedad. El legado historiográfico de Antonio Viñao, ed. Pedro Luis Moreno Martínez 197-213. Valencia: Tirant Humanidades, 2018.

Hamilton, David. Towards a Theory of Schooling. London: The Falmer Press, 1989.

Hillier, Bill y Julienne Hanson. The Social Logic of the Space. Cambridge: Cambridge University Press, 1984.

Markus, Thomas A. Buildings \& Power. Freedom and Control in the Origin of Modern Building Types. London: Routledge, 1993.

Martínez Ruiz-Funes, María José y Ana Sebastián Vicente, «Historia de la educación en y desde Murcia», en Educación, Historia y Sociedad, Educación, Historia y Sociedad. El legado historiográfico de Antonio Viñao, ed. Pedro Luis Moreno Martínez, 45-66. Valencia: Tirant Humanidades, 2018.

Monreal, Juan. «Contribución metodológica a una sociología del espacio. Producción del espacio escolar». Memoria para el acceso a la cátedra de Sociología. S.a., pero hacia 1985. Documento policopiado.

Monreal, Juan (dir.). Libro blanco de la Universidad de Murcia: análisis y perspectivas. Murcia: Instituto de Ciencias de la Educación, 1979.

Montenegro, Ana María. «Un lugar: la escuela pública. Origen y paradoja (Buenos Aires, Argentina, 1580-1910)». Tesis doctoral. Madrid, Universidad Nacional de Educación a Distancia, 2011.

Moreno Martínez, Pedro Luis. «Memoria escolar y patrimonio histórico-educativo», en Educación, Historia y Sociedad, Educación, Historia y Sociedad. El legado historiográfico de Antonio Viñao, ed. Pedro Luis Moreno Martínez, 385-428. Valencia: Tirant Humanidades, 2018.

Rodríguez Méndez, Francisco Javier. «Arquitectura escolar en España (18571936). Madrid como paradigma». Tesis doctoral. Departamento de Composición Arquitectónica, Universidad Politécnica de Madrid, 2004.

Rodríguez Méndez, Francisco Javier, María del Pilar García Salmerón y Antonio Viñao, «Las construcciones escolares en España en los años veinte y 
treinta del siglo pasado (la dictadura primorriverista y la Segunda República)», Historia y Memoria de la Educación 11 (2020): 649-673.

Rosa Gálvez, Juan. «Urbanismo y educación. El proceso de implantación de la Educación General Básica en el municipio de Alcantarilla (1970-1985)». Tesis doctoral. Murcia, Universidad de Murcia, 1990.

Trilla, Jaume. Ensayos sobre la escuela. El espacio social y material de la escuela. Barcelona: Laertes, 1985.

Varios autores. Arquitecturas en Valladolid. Tradición y modernidad, 1900-1950. Valladolid: Colegio de Arquitectos de Valladolid, 1989.

Varios autores. Ordenación territorial del Mar Menor y su entorno. Murcia: Centro de Estudios de Ordenación del Territorio y del Medio Ambiente, Ministerio de Obras Públicas y Urbanismo, 1985.

Viñao, Antonio. «El planeamiento urbanístico-docente: un análisis de sus necesidades y problemas», Revista de Educación 264 (1980): 69-80.

Viñao, Antonio. «Cartagena 1900. Los orígenes de la escuela graduada pública en España», en La educación en la España contemporánea. Cuestiones históricas. Libro de homenaje a Ángeles Galino, ed. Julio Ruiz Berrio, 144-150. Madrid: Sociedad Española de Pedagogía, 1985.

Viñao, Antonio. «Espacios masculinos, espacios femeninos. El acceso de la mujer al bachillerato", en Mujer y educación en España, 1868-1975. VI Coloquio de Historia de la Educación, 567-577. Santiago de Compostela: Universidad de Santiago, 1990.

Viñao, Antonio. Innovación pedagógica y racionalidad científica. La escuela graduada pública en España (1898-1936). Madrid: Akal, 1990.

Viñao, Antonio. «El espacio escolar. Introducción», Historia de la Educación, 12-13 (1993-1994): 11-16.

Viñao, Antonio. «Del espacio escolar y la escuela como lugar: propuestas y cuestiones», Historia de la Educación, 12-13 (1993-1994): 17-74.

Viñao, Antonio. "Construcciones y edificios escolares durante el sexenio democrático (1868-1874)», Historia de la Educación, 12-13 (1993-94): 493594.

Viñao, Antonio. "El espacio escolar en su perspectiva histórica. Bibliografía», Historia de la Educación, 12-13 (1993-94): 573-594.

Viñao, Antonio. Espacio y tiempo. Educación e historia. Morelia: Instituto Michoacano de Ciencias de la Educación, 1996.

Viñao, Antonio. «Lugares y tiempos de la escuela», Vela Mayor/Revista de Anaya Educación 11 (1997): 61-69.

Viñao, Antonio. «L'espace et le temps scolaires comme objet d'histoire» Histoire de l'Éducation 78 (1998): 89-108. Versión en español: «El espacio y el tiempo escolares como objeto histórico», Contemporaneidade e Educação V, no. 7 (2000): 93-110. 
Viñao, Antonio. «Espacios escolares, funciones y tareas: la ubicación de la dirección escolar en la escuela graduada», Revista Española de Pedagogía LXII, no. 228 (2004): 279-303. Versión ampliada en inglés: «The School Head's Office as Territory and Place: location and physical layout in the first Spanish graded schools», en Materialities of Schooling. Design - TechologyObjects - Routines, eds. Martin Lawn \& António Nóvoa, 47-70. Oxford: Symposium Books, 2005. Traducción al portugués: «Espaços, usos e funções: a localização e disposição física da direção escolar na escola graduada», en Història da Educação, Arquitetura e Espaço Escolar, orgz. M. L. Albino Bencostta, 15-47. São Paulo: Cortez Editora, 2005.

Viñao, Antonio. "Templos de la patria, templos del saber. Los espacios de la escuela y la arquitectura escolar», en Historia ilustrada de la escuela en España. Dos siglos de perspectiva histórica, dir. Agustín Escolano, 47-71. Madrid: Fundación Germán Sánchez Ruipérez, 2006).

Viñao, Antonio. «El espacio escolar: viejas cuestiones, nuevos escenarios», en Historia ilustrada de la escuela en España. Dos siglos de perspectiva histórica, dir. Agustín Escolano, 209-308. Madrid: Fundación Germán Sánchez Ruipérez, 2006.

Viñao, Antonio. "La escuela y sus escenarios en la España del siglo XX: el espacio y la arquitectura escolar», en La escuela y sus escenarios, eds. Juan Gómez Fernández, Gloria Espigado Tocino y Miguel Beas Miranda, 9-36. El Puerto de Santa María: Concejalía de Cultura del Ayuntamiento de El Puerto de Santa María, 2007.

Viñao, Antonio. «Escolarización, edificios y espacios escolares», Participación Educativa 7 (2008): 16-27.

Viñao, Antonio. "Espacio, sociedad, educación (entre la memoria y el olvido)», en Sociologías y economía. Homenaje al profesor Juan Monreal, 33-47. Murcia: Editum, 2014.

Viñao, Antonio. «El espacio escolar ¿Cómo abordar un objeto polifacético y multiforme?», en Espacios y patrimonio histórico-educativo, coords. Pauli

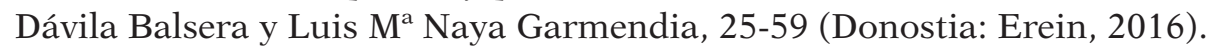

Viñao, Antonio. «El plan quinquenal de construcciones escolares de 1957$1961 »$. Vic, Universidad de Vic, 2018. En http://mon.uvic.cat/araef-conceptual-challenges/2018/09/07/antonio-vinao-frago-el-plan-quinquenal-de-construcciones-escolares-de-1957-1961/.

Viñao, Antonio. "Escuela graduada y medio urbano: construcciones, edificios y grupos escolares (1898/1936)» $\mathrm{y}$ «Graded schools in the urban settings: constructions, buildings and school complexes (1898/1936)», en Madrid, ciudad educadora 1898/1938. Memoria de la escuela pública, 168-265. Madrid: Ayuntamiento de Madrid. Oficina de Derechos Humanos y Memoria, 2019. 
Viñao, Antonio. «Política educativa, escolarización y construcciones escolares en España (1969-1970», Artigrama, 34 (2019): 25-45.

Viñao, Antonio y Agustín Escolano, Currículo, espaço e subjetividade. A arquitectura como programa. Rio de Janeiro: DP\&A Editora, 1998.

Viñao, Antonio y Marcus Levy Bencostta, "Ente a multidisciplinariedade e a história: o espaço e a arquitectura escolares nas recentes historiografias educativas espanhola e brasileira», en História(s) Comparada(s) da Educação, orgz. Marta Maria de Araújo, 23-51. Brasilia: Liber Livro Editora Ltda., 2009. 